produce the worst species of mercurialism, if they are diffused through an apartment not sufficiently ventilated."

With those facts before us, it appears to me that in the case under consideration, the indicatio cansalis, was completely fulfilled; and that there is no reason to deny, on any sound principle, this apparent agreement of theory and experience. Neither can any exception be taken against this conclusion, on the ground of the inadequacy of the dose that could be received in this way, to produce such effects; since the experience of every practitioner will afford an answer, in the well known extreme susceptibility in some constitutions of the action of the medicine in any form. Cases are recorded of severe effects, and even death, having been occasioned by small doses (Sigmond, Loco Citato, p. 294). Some years ago I prescribed calomel in doses of a twelfth of a grain daily, for an adult male patient, and he was compelled to discontinue the medicine before he had taken half a grain, in consequence of his mouth having become affected. In another instance one of the most severe cases of salivation I ever saw was occasioned by a few grains of the hydrarg. c. cretâ. But the most remarkable instances of this kind, that I remember to have met with, are mentioned by the late Dr. M'Intosh,* of Edinburgh, who states that his patients in the hospital, at the castle, using the black wash to venereal sores on the penis, became constitutionally affected without any other mercurial treat. ment.

There are some other circumstances attending this case which ought to be noticed. 'The room in which the mother lay, was small, very low pitched, and, being in the roof of the house, it had coved or sloping walls nearly from the floor to the ceiling on two sides. There was but one small casement window, and the only access to the apartment was by a hole in the floor, so small that it was approached by a perpendicular ladder. It is obvious that ventilation in such a place could be but very imperfectly maintained. Moreover, the weather was then, and had for some time before, been very damp and wet, and this, occurring at the hottest season of the year, formed a conjunction of circumstances the most favourable to the action of mercury on the system.

It is presumed, therefore, that the facts adranced, and the reasoning deduced from them, are sufficient to justify the conclusions which appear to me inevitable from the foregoing relation.

I need not further occupy the time of the society, by remarking upon the importance to the profession of the knowledge that such an occurrence may take place, as questions in connection with it might arise -both in a medico-legal point of view, and affecting the credit of the practitioner.

P.S.-I am happy at being permitted to send you also the history of a similar case, kindly furnished me by $\mathrm{Mr}$. Boulger, in whose practice it has since occurred. He brought it forward at a subsequent meeting of the society, and it was considered by the members to be a valuable confirmation of mine.

"London-strect, Jan. 12, 1812

My dear Sir,-I am sorry that I could not find time to send you the annexed history before, but I trust it will not come too late for any purpose you may require it.

It is a very strong case, and there can be no mistake about it.

\section{Belicve me,} My dear Sir, Yours faithfully,

To E. D. Walker, Esq. Edward Boulger.

Nov. 29, 1841. I was sent for to Mrs. Collins. Three weeks ago her husband, a painter and glazier, was

* Practice of Physic, second edition, vol. ii., p. 298. under my care for an attack of colica pictonum. Inflammatory symptoms having supervened, I was obliged to resort to mercurials, and his gums were rendered slightly tender, and maintained in that state for a few days, when the remedies were discontinued, and he speedily recovered.

His wife (they had been married only two months) had nursed him throughout the illness with much care and assiduity. She was in good health until two or three days before I saw her, when she began to feel her mouth and gums sore, and her breath fetid. She then took a few grains of magnesia ont of a bottle, but finding no relief from it, I was called in. I found her profusely salivated; the mercurial fotor was excessive, and ulceration of the gums had likewise commenced, and was with difficulty checked by acid hydrochlor. fort. and argent. nit., with senna draughts and sulphur sublimat.

The bottle of magnesia I securcd, and its contents proved genuine and madulterated. The patient had enjoyed such health that she had taken no kind of medicine for a year or more previously.-E. B."

\section{SOME ACCOUNT}

of A

\section{NEW REMEDIAL AGEN'T}

ByConwaY J. Enwards, M.R.C.S., Batheaston, Bath.

The addition to our very extended catalogue of medicines, to which I would wish to draw the attention of the profession, is of a nature so simple, that medical gentlemen will rather be inclined to doubt its possession of any medicinal properties than to believe that it contains those which can effect great and beneficial changes in diseases, which frequently baffle the most eminent of the profession. Indeed, the very name of "clinkers" (under which title I beg leave to introduce it) is calculated to set the seal of condemnation on the substance, without affording it the benefit of further consideration; nevertheless, in face of the great obstacle to a "fair hearing," which such a name must of necessity impose, I have no hesitation in advancing an opinion, that its powers as a tonic and colorific are of no mean order; and this statement is supported by the experience of Dr. Watson, of Bath, who was the first initiated in the mystery of its preparation, and the first to sanction its use.

"Clinkers" is the refuse of the blacksmith's forge, and differs from common ashes and coke in its greater specfic gravity, component parts, and external appearance. As a medicine in cachectic disorders, particularly those of females, it has been used for many years, by "knowing old women" in certain manufacturing districts; and the success which attends its exhibition, paticularly in chlorotic disorders, is such as to have won for it the title of "specific."

'The following is the formula for its preparation :The bluest and heaviest clinker, being selected from a mass, is reduced to an impalpable powder (a work of no small dificulty, on account of its metalloid nature). Any quantity of this powder may be mixed, with a sufficiency of treacle, to form a stiff paste; and to every eight ounces of the mass half an ounce of magnesia, and the like quantity of ginger, must be added. 'Thus formed, it is any thing but inviting to the cyc; but this can be remedied by using honey in lieu of treacle, and adding half a drachm of the peroxide of iron to the compound.

The directions which accompanied the formula were as unique as the formula itself. It must be taken three successive days and nights (twice a day), for three days ; omitted for a like period, and so continued until the course which has been decided upon should 
be finished. The dose is a teaspoonful. Absurd as these directions seem, they are not so ridiculous as they appear, for experience has demonstrated that constitutional irritation supervenes, unless some decided interval is allowed at stated periods during a course of this remedy.

'The first time I heard of this medicine was, after it had effected a happy change in the constitution of a young lady, who had been suffering from some internal but obscure disorder, for several years. The circulation, through the minute ramifications of the blood ressels, was reduced to its lowest ebb, while the fluid which circulated in the larger channels was a turbid brown, instead of the rich colour for which blood is remarkable. Under such a state of things, the exsanguineous appearance of the skin may be readily conceived. She had been under the professional care of two medical men before I was consulted, and, when called in, found her suffering from all those symptoms of debility, which characterise uterine and ovarian disturbance. From some remarkable symptoms, I was led to fix the seat of the disease in the ovaries. During my attendance I tried every medicine, and combination of medicines, which bore upon the case ; but no permanent benefit resulted from any of them : the only preparations which produced a tolerable effect were those of iron, and among them none possessed such power as the ioduret. The constitution became evidently impaired; the feet swelled; there was distention; and disorganisation appeared to be making rapid advances. A rery distinguished physician was called in, but could give no opinion on the nature of the case. He attended for several weeks with no success; during this gentleman's attendance, most agonising pains in the head came on; they were neuralgic; for the relief of these a veratrine ointment was applied; then veratrine delphia and morphine, suspended in oil; $x$ ther and ammonia were rubbed in : all these failed. I then proposed passing an electric current through the affected part, to which assent was given, but with a similar result. Le Fai's ointment was advised by some friend, and, I must certainly admit' with partial success. I never witnessed sufferings so acute-so continued. Another eminent physician was now consulted. "We must," he said, "build up the constitution; it will be a work of time, but it must be done." And a work of time it might have been, for after a considerable attendance no radical good was effected. Still, the principle on which this gentleman acted was sound, and although, as regarded the original affection, things had not improved, there was no retrograde movement, and possibly there might have been an important and visible advance, had the attendance extended over three or four years. Brighton was resorted to, and failed; the Isle of Wight, Clevedon, and several other maritime places, tried; but in vain. Medicine, diet, and change of air, were alike unavailing. Dr. Watson, of Bath, was called in, but no decided opinion could be pronounced, and, consequently, no very decided plan of treatment adopted. The case seemed hopeless, when a young lady, whose sufferings had been similar to those of this patient, and whose case had baffled the skill of her professional advisers, recommended her to have recourse to the remedy which had restored her to health; a large number of cases were also adduced in favour of its efficacy. The offer was eagerly embraced, and, Dr. Watson's consent being obtained, the tria of the " clinker" commenced.

The result exceeded all expectations. In two months the feet ceased to swell; the tumidity of the hypogastric and umbilical regions subsided; the functions of the stomach were restored; the small wiry pulse of above 100 was converted into a healthy beat of 80 ; the neuralgic pains ceased; and, what was most extraordinary and pleasing, the capillary circulation became so improved, that the skin assumed a vital hue, and the cheeks denoted returning health; every morbid symptom disappeared, except an excess of uterine secretion. 'The happy change surprised the professional attendants, as well as the patient's friends and relations, and, without being at all enthusiastic in praise of the " clinker," it may be fairly admitted that the beneficial results in this interesting case were owing to its medicinal properties.

Its success here made me anxious to test its powers further; and the lady having been so obliging as to give me the formula for its preparation, several patients were collected in whom the exsanguineous state of the skin, and wasting of the muscular fibre, were indicative of the morbid manner in which the functions of the stomach, alimentary canal, and uterus were carried on. Within a month from commencing the use of the clinker, a striking improvement took place in the appearance of the patients, and before the termination of two months every unfavourable symptom disappeared. One case, in particular, is well worthy of especial notice, by reason of the scrofulous condition of the submaxillary glands, and the ulcerated state in which one of them had been for several years, and which healed during the course of the new medicine.

I may observe, en passant, that previously to a trial of the clinker, this young woman had been under professional treatment for some time, without deriving any benefit from it.

The pulse was weak, and nearly 100 ; catamenia irregular in appearance, variable in quantity, and unnatural in composition; appetite and sleep bad; tongue foul; and what, perhaps, may be termed hysterical hypochondriasis, existed to a great degree. A gentle cathartic of infusion of senna, with tartrate of potass, was given for a few successive days before the clinker was commenced. She had not taken the new medicine six weeks, when most of the distressing symptoms disappeared, and her personal appearance became so improved, that her friends scarcely recognised in the ruddy girl before them the pallid and unhealthy creature she had once been.

It appears greatly to benefit cases of simple indirestion, a few doses being capable of removing the most distressing symptoms. In that peculiar condition of the secretion of the bowels, which is said to favour the formation or propagation of worms, it has proved advantageous in two ways-one, by its mechanical action; the other, by its tonic properties. This was an accidental discovery, made during its trial in a case of leucorrhœa.

When the medicine is taken for the first time, a train of symptoms frequently supervenes, which would induce a stranger to its modus operandi to regard it as a dangerous compound. A great weight is felt in the epigastric region, accompanied with a burning sensation; sensations of sickness, followed by those of faint ing, come on; these are soon relieved by eructations of flatus. Some complain of pains in the limbs, and particularly the joints; others of tightness across the forchead, with giddiness; while all are troubled with heat, dryness of the mouth, and great thirst. At the second dose the symptoms are moderated, and the third is generally taken with impunity. After it lias been persevered with for a short time, sensations of a different character arise; these are hunger, and a feeling of health and energy, to which, perhaps, the patient has been a stranger for many years; then the complexion, if pale, commonly receives a ruddy tint, and the muscular fibre becomes firm and enlarges. After the first dose the foces are like pitch, the urine generally pale, and large in quantity; the bowels, it previously costive, become regular in their action; the pulse gets full, and the skin pleasantly relaxed.

'To sum up its medicinal properties, it may be said that the clinker is tonic, stimulant, anthelmintic, and colorific, adapted generally to a leucophlegmatic habit, and, where dyspeptic, chlorotic, and scrofulous complaints exist, "its use would be contraindicated where an inflammatory diathesis prevails." 
The quantity of metal which clinker contains varies considerably ; the best is obtained from a blacksmith's forge, and the most ponderous, darkest, and metallic in appearance, is that only on which dependance can be placed. The light, slate-coloured clinker is inert.

I need not offer any remarks on the magnesia and ginger, which are added in the formation of the linctus; but I may observe, that if the ginger be omitted, violent griping ensues. After the medicine has been given for a few wecks, no bad symptoms arise if it is exhibited more frequently than at the beginning of the course.

From the imperfect analysis which I have made of the clinker, I should say that, with the usual substances found in coal partially decomposed by heat, a metalline appearance pervades the mass, which scems to be iron combined with carbon, so as to form steel ; no doubt the metal exists likewise, both as a sulphuret and a carbonate of the protoxide, but neither of these would afford the blue tint for which the clinker is remarkable. That it is not titanium is evident, for that metal is "like burnished copper," and so little fusible, that the heat of the oxyhydrogen blowpipe, when in action, is scarcely able to touch it-at least, if we may believe our professors. If, therefore, the heat of highly compressed gases intimately mingled be just capable of oxidyzing titanium, can we expect that the fire of the common forge would do so? From whence, then, do we get titanic acid ? Surely not in or from the various new compound bodies which are formed during the decomposition of the coal! Here we have first a mass of small coal, with, perhaps, charcoal, kindled into a flame; over this water is thrown, the decomposition of which increases the heat. When the temperature is at its maximum, a bar of soft iron is plunged into the centre, and rapidly reaches the temperature of the surrounding substances; particles of highly ignited metal are thrown off; some in a semifused state unite with particles of carbon, and perhaps form steel; others combine immediately with the oxygen of the water, and become a protocarbonate of the protoxide, while other portions form a sulphuret, and appear through the whole mass as new compounds endued with new properties, which had no pre-existence before the interchange of elementary principles. But this is not all; as the coal is decomposed it is raked off and thrown on one side, fresh supplies being added, until every component particle of the iron is raised to a white heat; it is then taken from the fire, placed on an anvil, and subjected to a succession of blows from the sledge hammer; this drives off large flakes of metal, many of which bury themselves in the masses of coke which have been cast aside, and are known as " clinkers." Now, if a portion of this be mixed with nitrate of potass, and strongly heated, a brown powder is formed, in which (had titanium existence) would be mingled the white peroxide; a solution of gall nuts would then produce the orange red colour; which is said to be characteristic of titanium; and were a rod of zinc suspended in the solution, a purple-coloured powder would be precipitated In making the experiments, I strictly adhered to the rules laid down for testing its presence, but perhaps, as I did not discover titanium or its oxide, it was owing to want of dexterity in the manipulations.

That the singularly beneficial effects which the clinker produces in certain conditions of the system cannot result solely from the iron or steel which it contains, the experience we have of those metals, and their preparations, sufficiently declare; some new combination must exist, to effect such singular changes; what it is remains to be proved. Electricity has been advanced as the cause, but even admitting that galvanic currents could be generated, they would be so weak in power, and small in quantity, as to be incapable of producing any results, while their source would prove so limited, that the electric evolution would cease before the linctus could be formed.

This is all which I have to advance on the subject at present. I must apologise for the imperfect manner in which it has been treated, yet hope that those members of the profession who have honoured these observations with a perusal, will direst themselves of all prejudice against the use of so humble a preparation, and give it that impartial trial which it would seem to deserve,

January $18,1842$.

PROVINCIAL

\section{MEDICAL \& SURGICAL JOURNAL}

\section{SATURDAY, FEBRUARY 5, 1842.}

Of the many repellant features which distinguish that disgrace to our legal code, known under the name of the Poor Law Amendment Act, there are none so heartless, none so repugnant to the best feelings of our nature as that portion of it which relates to the treatment of the helpless infant. The outrage which is inflicted upon all domestic feelings, by the separation of husband and wife, of parent and child, is not merely grievous wrong in itself. It is an infliction which presses most unequally-lightly esteemed, perhaps, by the dissolute and undeserving, but severely felt by those who are real and fitting objects for public assistance. By the former class it is scarcely if at all felt, while upon some of the latter it operates even more strongly than any other provision adopted in the workhouse system, in reducing them to the extreme of destitution before they will accept of relief upon workfouse terms. How many instances might be enumerated, where families have endured all but absolute starvation before they could be induced to apply for the relief which they so much needed solely on account of this odious measure! Instances have come within our own knowledge, where a whole family has gone without food for two or even three days, from the dread of separation under these afflicting circumstances.

The moral effect also is most injurious both upon the forlorn and destitute beings who are compelled to suffer from the law as it now stands, and upon the guardians who are called upon to enforce it. 'To encourage the domestic relations, the feelings of sympathy and affection which should exist in the married state, and the mutual attachment of parent and child, should be a chief object with a paternal and enlightened government, and nothing which can interfere with these first of moral and social obligations should be tolerated. But to put a force upon the warmest and best affections of man, with the view of making them subservient to the carrying out of a principle, fallacious in itself, impolitic in its essence, and equally opposed to humanity and religion, is indeed a solecism which requires a deep insight into human nature to comprehend. Is it that those who made and those who administered the poor-law are insensible to the 